\title{
Para compreender o antifascismo na América Latina
}

\author{
José Luis Bendicho Beired
}

OLIVEIRA, Ângela Meirelles. Palauras como balas. Imprensa e intelectuais antifascistas no Cone Sul (1933-1939). São Paulo: Alameda, 2015.

Durante a Primeira Guerra Mundial, poucos imaginavam que estava em gestação um novo movimento político radical de direita capaz de alterar profundamente a política internacional. Ao tomar o poder na Itália, o fascismo foi a primeira experiência de extrema-direita a mostrar que era possível não só derrotar o status quo liberal mas também barrar a ascensão das forças de esquerda. Em seguida, outros movimentos de direita se alastraram pelo continente europeu, quer tomando o poder quer organizando-se em novos partidos. Para o filósofo alemão Oswald Spengler, vivia-se uma fase histórica em que se divisava a própria decadência do Ocidente. As reaçóes foram tardias, pois apenas nos anos 1930 a direita radical deixou de ser combatida isoladamente pelas forças políticas de cada país e passou a ser objeto de luta de um movimento antifascista internacional que galvanizou um conjunto de forças formado por intelectuais, organizaçôes e órgãos de imprensa.
O livro de Ângela Meirelles Oliveira constitui uma inovadora contribuição para a compreensão do papel da América Latina na cruzada internacional de combate ao fascismo. Com base em minuciosa pesquisa documental realizada em diversos países, o estudo oferece novos elementos a respeito dos movimentos antifascistas do Brasil, da Argentina e do Uruguai por meio de um recorte que privilegia o papel dos intelectuais e a atuação da imprensa. O título da obra, extraído de um verso emblemático - Palabras como balas hay que usar contra vosotros, enemigos! - da poetisa argentina Nydia Lamarque, por si só ilustra o espírito do engajamento que tomava os intelectuais empenhados na causa antifascista.

A metodologia empregada constitui um dos pontos altos da obra. Articulando o método comparativo e a perspectiva transnacional, a autora estabelece recortes criativos, reconstrói conexôes e apresenta conclusōes que permitem explicar as peculiaridades do antifascismo no Cone Sul e as suas relaçóes com o movimento antifascista europeu. Um aspecto fundamental da abordagem reside no tratamento dos intelectuais como mediadores do processo de circulaçấo de ideias 
entre os países do Cone Sul e entre estes e a Europa, em especial a França. Sob a vigilância metódica das autoridades policiais, os intelectuais sustentaram a luta antifascista por meio da fundação de entidades, criação de órgãos de imprensa, elaboração de artigos, troca de correspondência, promoção de campanhas e exposiçóes de arte.

Uma tese basilar perpassa o livro pondo em xeque interpretaçóes consagradas na historiografia: a despeito da relevância das organizaçóes europeias e da URSS para o antifascismo latino-americano, este teria se desenvolvido com relativa autonomia em função dos contextos nacionais. Não obstante, a autora reconhece que as organizaçóes criadas na Europa tiveram papel central no engajamento mundial dos intelectuais na luta contra o fascismo. Fundadas por militantes e simpatizantes de esquerda, as organizaçóes europeias gravitaram, não sem tensão, em torno da Comintern e, consequentemente, dos interesses soviéticos em relação à política internacional, a exemplo do Comitê de Vigilância de Intelectuais Antifascistas e da Associação de Escritores e Artistas Revolucionários. Um papel de destaque coube ao Comitê Mundial contra a Guerra e o Fascismo por sua influência na Europa e na América, contando com a participação dos mais renomados intelectuais de então - Máximo Gorki, Bertrand Russell, Albert Einstein, John Dos Passos e André Gide entre muitos outros — sob a direção dos franceses Romain Rolland e Henri Barbusse.

A primeira parte do livro é dedicada ao exame das organizaçóes, intelectuais e ór- gãos de imprensa antifascistas do Cone Sul. No Brasil, as primeiras a serem fundadas foram os Comitês Antiguerreiros de São Paulo e do Distrito Federal, de filiação comunista; e a Frente Única Antifascista, criada na sede do Partido Socialista Brasileiro, com a participação da Liga Comunista Internacionalista, de perfil trotskista. As tensôes entre fileiras fascistas e antifascistas não eram pequenas. Em 1934, ambas confrontaram-se fisicamente quando as agrupaçóes antifascistas se concentraram na Praça da Sé, centro de São Paulo, para protestar contra um comício organizado pela Ação Integralista Brasileira, deixando um saldo de seis mortos e dezenas de feridos dos dois lados.

Vinculado à Frente Única Antifascista foi criado o Clube dos Artistas Modernos, que promoveu a famosa conferência de David Alfaro Siqueiros a respeito da técnica muralista em São Paulo, por ocasião da sua passagem pelo Brasil ao retornar do Rio da Prata para o México. Outras experiências, o Clube de Cultura Moderna e o Centro de Defesa da Cultura Popular, associados à Aliança Nacional Libertadora, visavam ambos ao estabelecimento de contato entre os intelectuais e o grande público para a difusão das artes, da ciência e da literatura. Em busca de espaços alternativos para a promoção das artes, em 1935 o CDCP organizou a I Exposição de Arte Social no Brasil, com a participação de Portinari, Di Cavalcanti, Noêmia Mourão, Oswaldo Goeldi, Ismael Nery e Alberto Guignard. Tais entidades exemplificavam o esforço da geração modernista em conferir à arte um sentido ao mesmo tempo vanguardista, popular e comprometi- 
do com as questóes políticas. Paralelamente, a imprensa foi outro veiculo fundamental de resistência política e cultural antifascista, cuja atividade esteve concentrada em órgãos tais como Revista Acadêmica, Diretrizes e Cultura, Mensário Democrático, além de jornais como Marcha e o diário A Manhã.

Uma das hipóteses da autora é que o funcionamento das entidades antifascistas dependeu das condiçôes políticas de cada país do Cone Sul. No caso do Brasil, a dinâmica política da Era Vargas foi mais tolerante com as atividades da extrema direita, a exemplo do Integralismo, do que com as correntes de esquerda, objeto de sistemática vigilância, perseguição e prisóes. A repressão subsequente ao levante de 1935 e ao golpe do Estado Novo apenas aumentou ainda mais as dificuldades do antifascismo, com o desmantelamento do PCB, prisóes, fugas e exílio de militantes e intelectuais. A Argentina e o Uruguai foram os destinos mais procurados pelos exilados brasileiros, que transformaram Buenos Aires e Montevidéu nos seus principais centros de atuação no exterior, a exemplo de Carlos Lacerda na sua fase comunista.

A comparaçáo permite constatar que a Argentina abrigou o movimento antifascista mais significativo da América Latina, traduzindo-se em uma maior quantidade de organizaçóes, pessoas e órgáos de imprensa envolvidos do que em outros países da regiáo. Em 1930 o general José Uriburu desferiu um golpe de Estado que derrubou o governo da União Cívica Radical presidido por Hipólito Yrigoyen e implementou uma ditadura filofascista apoiada pelo exército e por milícias uniformizadas, tais como a Legião Cívica Argentina. Carente de suficiente base política, o poder foi passado aos conservadores, que restauraram o antigo sistema de eleiçóes fraudadas, primeiramente sob a presidência de outro militar, o general Agustín P. Justo, e depois o civil Roberto Ortiz, buscando-se manter uma posiçáo de neutralidade diante da contenda entre o fascismo e o antifascismo. Apesar das perseguiçóes contra militantes de esquerda, havia de qualquer modo mais condiçóes que no Brasil para a atividade política, a organização de movimentos e o funcionamento da imprensa antifascista. Um papel relevante, embora fora do âmbito da pesquisa do livro, foi desempenhado pelas coletividades de estrangeiros, notadamente a italiana e a espanhola, cujas atividades antifascistas foram estudadas no Brasil por João Fábio Bertonha e Ismara Izepe de Souza, e na Argentina, por Mónica Quijada e Andrés Bisso.

A segunda parte do livro dedica-se à circulação internacional das ideias e dos intelectuais antifascistas. A autora confere especial atenção à Agrupação de Intelectuais, Artistas, Jornalistas e Escritores por considerá-la a mais importante associação em prol do antifascismo. Criada primeiramente em Buenos Aires, e em seguida em Montevidéu, tinha como objetivo declarado "lutar pela defesa da cultura”, em outras palavras, combater o obscurantismo embutido náo apenas no fascismo internacional, mas também no autoritarismo e na corrupção política praticados pelos governos conservadores. A entidade argentina chegou a contar com 2 mil associados e diversas filiais no interior 
do país, tendo à frente figuras como Anibal Ponce, Sergio Bagú, Manuel Ugarge, Liborio Justo, Héctor Agosti e Arturo Frondizi, então jovem membro da União Cívica Radical e futuro presidente da nação. $\mathrm{O}$ boletim da entidade - Unidad por la defensa de la cultura - somou-se a várias outras publicações regulares que, embora não dedicadas exclusivamente ao antifascismo, o tomaram como causa própria, tais como Claridad, Hechos e Ideas, Sur e La Internacional.

Dois interessantes aspectos sobressaem. Em primeiro lugar, a diversidade ideológica das publicaçóes mencionadas - respectivamente socialista, radical, liberal e comunista -, assim como das organizaçóes antifascistas. A autora contesta enfaticamente a tese do caráter essencialmente comunista do antifascismo dos países estudados, assim como do papel determinante da Comintern na sua organização. No lugar disso, identifica a existência de uma matriz liberal no antifascismo argentino e, no caso do Uruguai, aponta uma forte politização, sem vinculação partidária. Em suma, a documentaçáo sugere que o vigor do movimento antifascista nos três países estudados dependeu justamente da heterogeneidade das suas fileiras e da amplitude do arco progressista que reunia liberais, anarquistas, radicais, comunistas, trotskistas e socialistas.

Outro aspecto a destacar é o papel das redes de sociabilidade antifascista que se estabeleceram por meio da imprensa vinculando as publicaçóes da Argentina, do Uruguai e do Brasil entre si e estas com as da França, epicentro internacional do movimento antifascista e sede de revistas como Clarté, Com- mune, Vigilance e Front Mondial. O intercâmbio ocorria pela reprodução de artigos e a notificação do recebimento de revistas de outros países, a exemplo de Commune, órgão da Associação de Escritores e Artistas Revolucionários, sediada em Paris, que recebia praticamente todas as revistas antifascistas sul-americanas. No Cone Sul, as revistas da Argentina e do Uruguai trocavam uma considerável quantia de matérias com as congêneres da França, o mesmo não ocorrendo com as revistas do Brasil, que apenas mantinham contato esporádico com as publicaçôes estrangeiras. Quanto ao intercâmbio intelectual entre os países latino-americanos, apenas existiu de modo rarefeito. Parece ter ficado mais no plano das intençôes que da sua efetivação material, apesar dos apelos da portenha Claridad e da baiana Seiva em favor do seu incremento.

O Uruguai merece um lugar especial em razão da relevância das atividades antifascistas em seu território. Em 1933, abrigou o Congresso Antiguerreiro Latino-americano de Montevidéu, que, vinculado ao seu homólogo europeu e à corrente comunista, congregou centenas de delegaçóes sindicais, camponesas, estudantis, de artistas e intelectuais. Náo deixa de ser notável a marca deixada por uma ilustre brasileira. Pelo prestígio pessoal e proximidade em relação ao PCB, Tarsila do Amaral foi uma das poucas intelectuais convidadas a proferir uma conferência, e, destoando do tom geral do evento, discorreu a respeito das "Mulheres e a guerra”. Encetando uma contundente crítica ao papel destinado às mulheres pelos governos capitalistas e imperialistas, terminou 
sob aplausos e conclamou-as à luta antiguerreira. A análise do congresso aponta, ainda, para as divisóes intestinas da esquerda e os diferentes conceitos de frente política, evidenciados nas críticas aos trostskistas, na expulsão dos anarquistas e na condenação de figuras como Augusto César Sandino e Haya de la Torre.

Às vésperas da Segunda Guerra, Montevidéu acolheu outro importante evento, o Congresso Internacional das Democracias. Composto por delegaçóes de intelectuais dos países americanos, foi patrocinado por um conjunto de partidos políticos uruguaios. Apesar da exclusão do Partido Comunista Uruguaio, a reunião contou com uma ampla participaçáo de delegados de todas as correntes políticas das Américas comprometidas com o antifascismo, incluindo o comunismo. Estiveram presentes personalidades como Pablo Neruda e Juan Marinello, que se reuniram em dezenas de comissóes para discutir assuntos políticos, econômicos, sociais e culturais. Também participou uma delegação brasileira não oficial composta por representantes da Universidade Nacional do Rio de Janeiro e das Mulheres Intelectuais do Brasil, além de brasileiros exilados perseguidos pelo Estado Novo, cujo governo buscou impedir sem sucesso a realização. Para a autora, o evento refletia a desilusão com a Europa e representou a inflexão do antifascismo latino-americano em vista do seu alinhamento às diretrizes da política externa norte-americana que enfatizava a boa vizinhança e a união das forças contrárias ao fascismo. O título do discurso do uruguaio Emilio Oribe era emblemático dessa guina- da: "Por que a América imita os europeus? Cultura autóctone e universal."

A autora dedica especial atenção à Guerra Civil Espanhola, conflito de enorme repercussão na América Latina e divisor de posiçôes da opiniáo pública, que se mobilizou tanto a favor do governo republicano quanto dos rebeldes nacionalistas. $\mathrm{Na}$ Argentina e no Uruguai a solidariedade aos republicanos foi especialmente intensa em razão da elevada taxa de imigrantes espanhóis em relação ao conjunto da população. Por sua vez, tais imigrantes estavam organizados em uma vasta rede de entidades associativas e jornais comunitários que impulsionaram iniciativas em favor da República Espanhola. As remessas de alimentos, remédios, dinheiro e roupas constituíram as açóes prioritárias da solidariedade aos republicanos, além da acolhida dos exilados e a pressão política pela não intervenção da Itália e da Alemanha no conflito espanhol.

Sáo examinadas as atividades da Agrupação de Intelectuais, Artistas, Jornalistas e Escritores, cuja seção argentina criou a Comissão Argentina de Ajuda aos Intelectuais Espanhóis. As açóes de solidariedade dessa comissáo tiveram como ponto alto os protestos e as homenagens decorrentes do fuzilamento de Gabriel Garcia Lorca, ato covarde que foi transformado em símbolo da luta da cultura contra a barbárie fascista. Os intelectuais latino-americanos viam a si mesmos como legítimos partícipes das fileiras republicanas deste lado do Atlântico. A uruguaia Clotilde Luisi, perguntando-se quem formava essa retaguarda, esse verdadeiro exército, guardiáo da alma espiritual do povo, res- 
pondia: os homens de ciência, professores, artistas plásticos, atores, escritores e poetas.

Em contraste, para a autora, a solidariedade dos brasileiros aos republicanos espanhóis não contou com a formação de entidades dedicadas especialmente a tal finalidade. Contando com a permanente repressão do governo Vargas, a solidariedade republicana apenas pode tomar corpo por meio de matérias divulgadas na imprensa antifascista e assim mesmo com restriçôes em vista da censura. Segundo o escritor Álvaro Moreyra, a morte de Garcia Lorca foi noticiada pelos jornais brasileiros com seis meses de atraso em outubro de 1937. De qualquer forma, a Revista Acadêmica foi a publicação brasileira mais empenhada no apoio aos republicanos. Após a vitória dos nacionalistas, expressou a dor da derrota e a consciência dos limites do papel do intelectual por meio de um artigo de Emil Fahrat: "Nossa dor é maior do que a tua, Espanha, porque fomos vencidos sem termos entrado na luta. Perdão Espanha pelo que náo fizemos por ti."

Apesar de atestar o vigor do antifascismo dos países do Cone Sul, o livro se encerra com a melancólica constatação do fracasso do movimento. Por um lado, os intelectuais desmobilizaram-se em razão do Pacto Germano-Soviético e da sua subordinação à Política da Boa Vizinhança. Além disso, eles se mostraram incapazes de enfrentar as medidas autoritárias dos governos brasileiro, argentino e uruguaio. Talvez seja um quadro por demais pessimista que poderia ser repensado se relacionado ao processo mais amplo de construçáo da democracia na América Latina. Sabe-se que a formação de uma cultura democrática, pluralista e defensora de direitos humanos básicos nos países latino-americanos é um fato inegável da sua história contemporânea. Porém, sob inúmeros percalços, não se manifestou de forma linear e nem da noite para o dia, constituindo antes um processo ainda inconcluso.

O exame do movimento antifascista sugere que ele contribuiu decisivamente para desenvolver uma cultura democrática que serviu de suporte para combater o autoritarismo em suas várias modalidades depois da Segunda Guerra Mundial. Por sua vez, a cultura política frentista, por vezes táo mal compreendida, pode ter justamente no antifascismo uma das suas raízes mais fecundas na América Latina.

\section{Como citar:}

OLIVEIRA, Ângela Meirelles. Palavras como balas. Imprensa e intelectuais antifascistas no Cone Sul (1933-1939). São Paulo: Alameda, 2015. Resenha de BEIRED, José Luis Bendicho. Para compreender o antifascismo na América Latina. Topoi. Revista de História, Rio de Janeiro, v. 19, n. 37, p. 226-231, jan./abr. 2018. Disponível em: <www.revistatopoi.org>. 